and, finally, by means of a totally endoscopic technique. It is important to note that when performing a totally endoscopic procedure, a quick and safe conversion to minithoracotomy under direct view can be made if circumstances demand, which would still offer significantly reduced chest trauma.

Totally endoscopic surgery in other fields, such as atrial septal defect repair and coronary artery bypass grafting, has shown improved quality of life but with longer clamping and CPB times during the learning curve., Considering that the TEAVR cases described here were our first procedures, we believe that clamping and CPB times were acceptable and suggest that the learning curve associated with TEAVR could be shorter than that reported with totally endoscopic coronary artery bypass grafting. The potential of this approach could be further enhanced by the development of endoscopic sizers as well as dedicated instruments for decalcification.

Second-generation sutureless bioprostheses could also simplify implantation, although this did not require more than 45 minutes in either patient. Devices to facilitate a technically demanding aortotomy closure are also critically important. In fact, closing the aorta consumed more than $30 \%$ of the clamping time in both cases, despite the fact that we selected patients with adequate working space around the ascending aorta. Last but not least, surgical robots may offer additional benefits to the totally endoscopic approach. Previously, only a proof-of-concept in cadavers ${ }^{5}$ through a standard minithoracotomy access has been published.

\section{CONCLUSIONS}

These first procedures show that totally endoscopic sutureless aortic valve replacement is technically feasible. Further clinical experience and technical development are necessary to shorten operation times and to assess further the potential postoperative benefits of TEAVR.

We thank Dr Antoine Gerbay and Dr Marie Levallois for the echocardiographic support.

\section{References}

1. EIBardissi AW, Shekar P, Couper GS, Cohn LH. Minimally invasive aortic valve replacement in octogenarian, high-risk, transcatheter aortic valve implantation candidates. J Thorac Cardiovasc Surg. 2011;141:328-35.

2. Glauber M, Miceli A, Gilmanov D, Ferrarini M, Bevilacqua S, Farneti PA, et al. Right anterior minithoracotomy versus conventional aortic valve replacement: a propensity score matched study. J Thorac Cardiovasc Surg. 2013;145:1222-6.

3. Morgan JA, Peacock JC, Kohmoto T, Garrido MJ, Schanzer BM, Kherani AR, et al. Robotic techniques improve quality of life in patients undergoing atrial septal defect repair. Ann Thorac Surg. 2004;77:1328-33.

4. Bonaros N, Schachner T, Lehr E, Kofler M, Wiedemann D, Hong P, et al. Five hundred cases of robotic totally endoscopic coronary artery bypass grafting: predictors of success and safety. Ann Thorac Surg. 2013;95:803-12.

5. Suri RM, Burkhart HM, Schaff HV. Robot-assisted aortic valve replacement using a novel sutureless bovine pericardial prosthesis: proof of concept as an alternative to percutaneous implantation. Innovations (Phila). 2010;5:419-23.

\title{
Sternal elevation before passing bars: A technique for improving visualization and facilitating minimally invasive pectus excavatum repair in adult patients
}

\author{
Dawn E. Jaroszewski, MD, ${ }^{\mathrm{a}, \mathrm{b}}$ Kevin Johnson, MD, ${ }^{\mathrm{a}}$ Lisa McMahon, MD, ${ }^{\mathrm{a}, \mathrm{b}}$ and David Notrica, MD, ${ }^{\mathrm{a}, \mathrm{b}}$ \\ Phoenix, Ariz
}

Minimally invasive repair of pectus excavatum (MIRPE) is performed by placement of substernal metal bars. Visualization across the mediastinum is compromised in severe defects, and cardiac puncture and aortic injury have been described. ${ }^{1}$ In adults with less chest wall flexibility, the

From the Division of Cardiothoracic Surgery, ${ }^{a}$ Department of Surgery, Mayo Clinic Arizona, Phoenix, Ariz; and Department of Surgery, ${ }^{\mathrm{b}}$ Phoenix Children's Hospital, Phoenix, Ariz

Disclosures: Authors have nothing to disclose with regard to commercial support. Received for publication April 18, 2013; revisions received July 10, 2013; accepted for publication Sept 25, 2013; available ahead of print Nov 18, 2013.

Address for reprints: Dawn E. Jaroszewski, MD, Mayo Clinic, 5777 E Mayo Blvd,

Phoenix, AZ 85054 (E-mail: jaroszewski.dawn@mayo.edu).

J Thorac Cardiovasc Surg 2014;147:1093-5

$0022-5223 / \$ 36.00$

Copyright (c) 2014 by The American Association for Thoracic Surgery

http://dx.doi.org/10.1016/j.jtcvs.2013.09.049 bars require more force to rotate and intercostal muscle stripping may result, leading to bar malpositioning. We present a technique to elevate the sternum and facilitate adult MIRPE.

\section{PROCEDURE}

The patient is positioned supine, rolls underneath, and arms tucked at sides. Bilateral incisions and subpectoral pockets are developed. Ports are placed through the incision and inferior-lateral above the diaphragm. Cardiac compression is assessed thoracoscopically. If safe dissection is potentially compromised by defect (Figure 1,A), a bone clamp is placed into the sternum and a table-mounted retractor is used to elevate the sternum (Figure 1, B). Patients with significant cartilage calcification and rigidity 

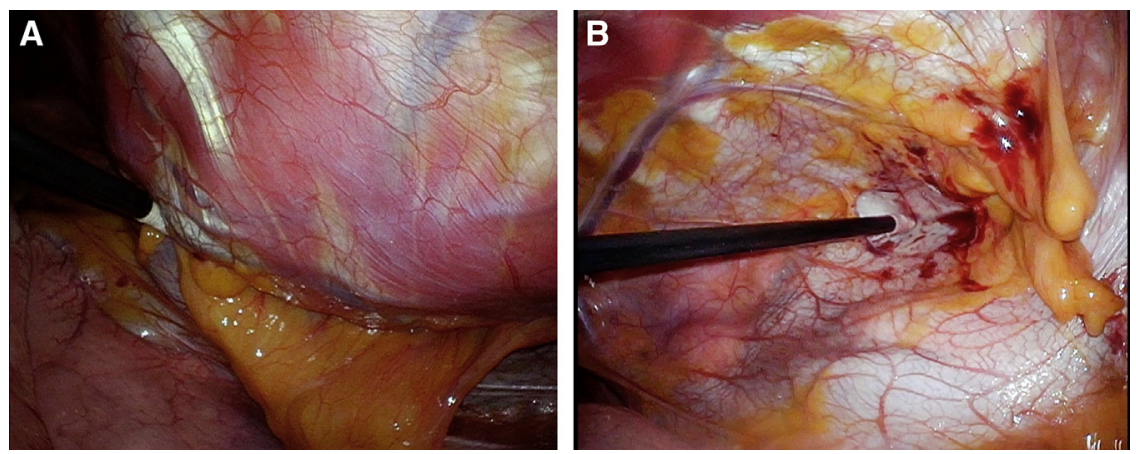

FIGURE 1. A, The anterior mediastinum is difficult to visualize, and instruments for dissection are deflected by the severe pectus excavatum defect. B, After elevation of the defect with the retractor, the anterior mediastinum is better visualized, and safe dissection across to the left thorax can be performed.

are also elevated before passing the dissector and bars. Puncture incisions in a rib space on either side of the sternum are made, and the perforating tips of a bone clamp (Lewin Spinal Perforating Forceps, V. Mueller NL6960; CareFusion, Inc, San Diego, Calif) are inserted (Figure 2, A). The Rultract Retractor (Rultract Inc, Cleveland, Ohio) with extension arm is attached to the left side of the table, approximately level with the clavicle. The cable is then attached to the clamp, and the sternum is elevated (Figure 2, B).

Dissection across the mediastinum into the left side of the chest is performed. The Lorenz dissector (Lorenz Surgical, Inc, Jacksonville, Fla) is then passed into a right anterior interspace, woven under the sternum, and guided up through a corresponding interspace on the left. A No. 5 FiberWire (Arthrex, Inc, Naples, Fla) is attached to the passer. The passer is withdrawn, and a pectus bar is guided into position with the FiberWire. The bars are rotated into place with the sternum still elevated to minimize transverse stripping of the intercostal muscle. Under thoracoscopic guidance, each bar is circumferentially attached to a rib at
2 to 3 sites with FiberWire. The sternal elevation is released, and the clamp is removed. The pectoralis muscles are closed over the bars, and the incisions are closed with absorbable suture. Two single skin stitches are placed at the sternal punctures.

\section{RESULTS}

From June 2010 to June 2013, a series of 185 patients underwent pectus excavatum repair. In 63 patients, Rultract was used for forced sternal elevation. With experience and standardization of our technique, sternal elevation with Rultract was used increasingly during pectus repair $(9 \%$ of cases 2010 through June 2012, 57\% of cases June 2012 through December 2012, 86\% of cases January 2013 through December 2013). Mean patient age was 33.4 years (range 18-71 years), and 138 patients were male $(75 \%)$. Procedures included 51 revisions of operations from other centers (30 open, 15 MIRPE, 6 multiple). The median Haller severity index of patients undergoing assisted sternal elevation was 5.5 , versus 4.7 for patients in whom sternal elevation was not used. Rigidity of the
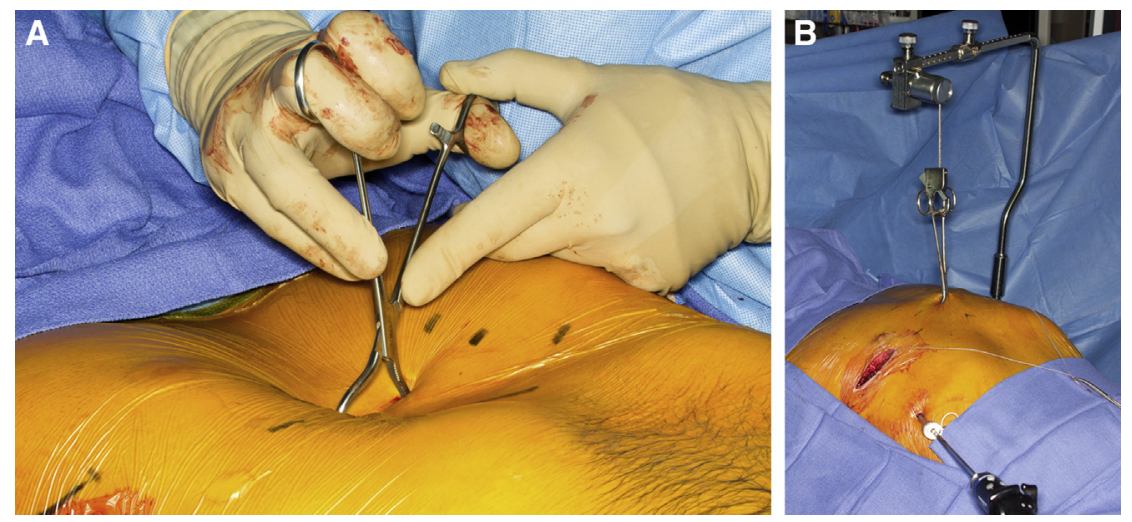

FIGURE 2. A, Stab incisions are placed on either side of the sternal defect, and the perforating tips of a bone clamp (Lewin Spinal Perforating Forceps, V. Mueller NL6960; CareFusion, Inc, San Diego, Calif) are inserted through the incision into the sternum. B, The Rultract Retractor (Rultract Inc, Cleveland, Ohio) with extension arm is attached to the bed at the level of the axilla on the left side. The cable is then attached to the clamp, and the sternum is elevated anteriorly. 
chest wall was an additional indication for sternal elevation in 47 patients. All patients had at least 2 bars placed for repair, and $33 \%$ had a third bar. Median operative time for MIRPE with Rultract was 122 minutes (range 45-274 minutes). There were no intraoperative complications. Two patients had ecchymosis at the site of bone clamp insertion that resolved without sequelae.

\section{DISCUSSION}

Visualization and dissection across the mediastinum in patients with severe excavatum is impaired by the inwardly displaced sternum. Forced mechanical elevation increases the anteroposterior dimension and facilitates dissection and visualization. Expanding the retrosternal space has been recommended by others to minimize pericardial trauma and eliminate cardiac perforation..$^{2-4}$ Other techniques require large incisions or blind dissection, although Yoon and colleagues ${ }^{5}$ have reported the use of wire stitches in the sternum.

We present a simple technique that requires minimal additional incisions or dissection to elevate the sternal deformity. This technique provides increased visualization and reduces stress on the intercostal spaces during bar insertion and rotation. Our use of forced sternal elevation has increased with experience, and this technique is now used in most adult MIRPE cases. We believe that this technique can facilitate safe dissection and bar passage as well as reduce the risk of intercostal muscle stripping in adult patients undergoing MIRPE.

We acknowledge Jesse Lackey for his contributions.

\section{References}

1. Bouchard S, Hong AR, Gilchrist BF, Kuenzler KA. Catastrophic cardiac injuries encountered during the minimally invasive repair of pectus excavatum. Semin Pediatr Surg. 2009;18:66-72

2. Johnson WR, Fedor D, Singhal S. A novel approach to eliminate cardiac perforation in the Nuss procedure. Ann Thorac Surg. 2013;95:1109-11.

3. Takagi S, Oyama T, Tomokazu N, Kinoshita K, Makino T, Ohjimi H A new sternum elevator reduces severe complications during minimally invasive repair of the pectus excavatum. Pediatr Surg Int. 2012; 28:623-6.

4. Tedde ML, de Campos JR, Wihlm JM, Jatene FB. The Nuss procedure made safer: an effective and simple sternal elevation manoeuvre. Eur J Cardiothorac Surg. 2012;42:890-1

5. Yoon YS, Kim HK, Choi YS, Kim K, Shim YM, Kim J. A modified Nuss procedure for late adolescent and adult pectus excavatum. World J Surg. 2010; 34:1475-80.

\title{
Minimizing chest wall trauma in single-port video-assisted thoracic surgery
}

\author{
Calvin S. H. Ng, MD, FRCS(CTh), Randolph H. L. Wong, MBChB, FRCS(CTh), \\ Rainbow W. H. Lau, MBChB, MRCS, and Anthony P. C. Yim, DM, FRCS, Hong Kong, China
}

Single-port video-assisted thoracic surgical (VATS) major lung resection for early stage lung cancer was first reported in 2011 by Gonzalez's group in Spain. ${ }^{1}$ This was a significant milestone and revolutionized the way VATS surgeons can further reduce access trauma by using only 1 incision port for lung resection. ${ }^{2}$ The success and adaptability of the single-port techniques in the treatment of various thoracic diseases have made them hugely popular around the world. ${ }^{3,4}$

\footnotetext{
From the Department of Surgery, Prince of Wales Hospital, The Chinese University of Hong Kong, Hong Kong, China.

Disclosures: Authors have nothing to disclose with regard to commercial support.

Received for publication Aug 6, 2013; revisions received Oct 15, 2013; accepted for publication Oct 25, 2013; available ahead of print Dec 2, 2013.

Address for reprints: Calvin S. H. Ng, MD, FRCS(CTh), Division of Cardiothoracic Surgery, The Chinese University of Hong Kong, Prince of Wales Hospital, Shatin,

NT , Hong Kong SAR, China (E-mail: calvinng@surgery.cuhk.edu.hk).

J Thorac Cardiovasc Surg 2014;147:1095-6

$0022-5223 / \$ 36.00$

Copyright (c) 2014 by The American Association for Thoracic Surgery

http://dx.doi.org/10.1016/j.jtcvs.2013.10.043
}

Despite minimal access approaches, thoracic surgical patients continue to be affected by significant acute and chronic postoperative pain. ${ }^{5}$ To address this problem, at least in part, we have previously described our maneuvers in minimizing chest wall trauma in conventional VATS, and these are also applicable to single-port VATS. ${ }^{5}$ Relative to conventional 3-port VATS, the single-port VATS technique is associated with fewer incisions and potentially less injury to fewer intercostal nerves. However, to fit all the instruments through 1 small incision and to allow them to reach the upper and lower extremes of the thoracic cavity during single port surgery, significant instrument torquing and nerve injury may occur. We have found the following useful to reduce port site trauma in our single port VATS lung resection practice:

1. We routinely use a $120^{\circ}$ thoracoscope, which allows magnified and unparalleled vision for the whole thoracic cavity. More importantly, the excellent field and degree of vision obviate the need to torque the thoracoscope in the single-port incision, which may reduce intercostal 